\title{
Transposition of IS117 of Streptomyces coelicolor A3(2) in Mycobacterium smegmatis
}

\author{
Apoorva Bhatt and Tobias Kieser
}

Department of Genetics, John Innes Centre, Norwich Research Park, Colney, Norwich NR4 7UH, UK

\author{
Author for correspondence: Apoorva Bhatt. Tel: +44 1603 452571. Fax: +44 1603456844. \\ e-mail : bhatta@bbsrc.ac.uk
}

\begin{abstract}
Derivatives of IS117, the Streptomyces coelicolor A3(2) $2.6 \mathrm{~kb}$ minicircle, transpose efficiently in Mycobacterium smegmatis, targeting chromosomal sites resembling translation start signals. Two IS117 derivatives, pIJ4696 and pIJ4697, containing a Streptomyces hygromycin-resistance gene in opposite orientations were introduced into $M$. smegmatis by electroporation and found to integrate into one of three specific sites. Integrations at sites A and B were frequent while integration at site $C$ was observed only once. Only one site was occupied in each transformant. Sites $A$ and $B$ had either single or tandem integrations. PFGE analysis located these sites on different genomic Asel fragments. The sequences of the chromosome-IS117 junctions confirmed that integration was via the same IS117 attachment site as in Streptomyces, that there was no target site duplication, and that the orientation of IS117 at each site was fixed. In contrast to the situation in Streptomyces lividans, no deletions were created by the transposition and no circular forms could be detected. Comparison of the three $\boldsymbol{M}$. smegmatis chromosomal IS117 target sites $\left(a t t_{B}\right)$ with known primary and secondary $S$. lividans $a^{a t t_{B}}$ sites showed that only a 2 bp 'AG' sequence at the crossover point was conserved. Dividing the att ${ }_{B}$ sites into two groups produced two longer consensus target sites, GtCAAGg and gCCGATAGg. Most of the IS117 target sites resemble translational start sites, and site $C$ resembles strongly the amino-terminal sequence of a Mycobacterium tuberculosis aminopeptidase. The level of hygromycin resistance in the transformants was high and independent of the site of integration, the number of copies integrated, or the orientation of the hyg gene. plJ4696 at all three sites was stable in $M$. smegmatis in the absence of selection for at least 60 cell divisions. pIJ4696, pIJ4697 and other IS117 derivatives are promising vectors for the stable, integrative cloning of genes in $M$. smegmatis.
\end{abstract}

Keywords: $2.6 \mathrm{~kb}$ minicircle, hygromycin resistance, site-specific integration, consensus target sites, PFGE

\section{INTRODUCTION}

The 2527 bp element IS117 of Streptomyces coelicolor A3(2) forms a covalently closed circular transposition intermediate, the ' $2.6 \mathrm{~kb}$ minicircle' (Henderson et al., 1989; Lydiate et al., 1986). It encodes a transposase gene which is similar to those of IS110 (Bruton \& Chater, 1987) and IS116 (Leskiw et al., 1990) of Streptomyces, IS900 of Mycobacterium paratuberculosis (Green et al.,

Abbreviations : att $_{\mathrm{B}}$, bacterial (chromosomal) IS117 attachment site; $a_{t t_{\mathrm{M}}}$ IS117 (minicircle) attachment site.
1989), IS492 of Pseudomonas atlantica (Bartlett \& Silverman, 1989), IS1000 of Thermus thermophilus (Ashby \& Bergquist, 1990) and several putative transposases of mycobacteria (Kunze et al., 1991; Moss et al., 1992), Rhodococcus (Kulakova et al., 1997), Coxiella (Hoover et al., 1992), Moraxella (Fulks et al., 1990), Agrobacterium (Zhu \& Winans, 1998), Rhizobium (Freiberg et al., 1997) and Yersinia (Rakin \& Heesemann, 1995). IS117 and its relatives lack terminal inverted repeats and do not create target site duplications. Streptomyces lividans, a close relative of $S$. coelicolor, lacks IS117 but contains a single preferred attachment site, $a t t_{\mathrm{B}}$, which is identical to one of the 
IS117 attachment sites of S. coelicolor (Henderson et al., 1989). The only sequence identity between the IS117

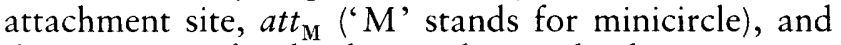
the $a t t_{\mathrm{B}}$ sites of $S$. lividans and S. coelicolor is TAG at the crossover point. Most S. lividans transformants contained two adjacent tandem copies of IS117 which originated from independent elements that were introduced into the same cells by co-transformation (Smokvina et al., 1994). Transformation of an S. lividans strain lacking att $_{\mathrm{B}}$ gave integration into secondary attachment sites at a reduced frequency (Henderson et al., 1990). Interestingly, integration into secondary IS117 attachment sites produced large chromosomal deletions extending from the sites of insertion (Smokvina \& Hopwood, 1993).

Streptomycetes are taxonomically related to the mycobacteria: both are high $\mathrm{G}+\mathrm{C}$, Gram-positive actinomycetes. Streptomyces transposable elements are thus likely to function in mycobacteria. Here we show that IS117 transposes into at least three chromosomal attachment sites in Mycobacterium smegmatis $\mathrm{mc}^{2} 155$, two of which are used preferentially. The DNA sequences of the sites resemble those of the primary and secondary Streptomyces attachment sites. Integration did not cause deletions in $M$. smegmatis. The integrated elements were maintained stably without selection, suggesting that IS117 derivatives may be useful as shuttle cloning vectors for Mycobacterium and Streptomyces.

\section{METHODS}

Bacterial strains, transformation and media. The Mycobacterium smegmatis strain $\mathrm{mc}^{2} 155$ (Snapper et al., 1990) was grown in $7 \mathrm{H} 9$ broth (Difco) containing $0.05 \%$ Tween 80 and $5 \%$ ODAC supplement (Difco; ODAC contains oleic acid, dextrose, albumin and catalase). Electroporation of $\mathrm{mc}^{2} 155$ was done as described by Snapper et al. (1988, 1990). After the $2500 \mathrm{~V}$ electric pulse, the cells were diluted in $5 \mathrm{ml}$ supplemented $7 \mathrm{H} 9$ broth and incubated with shaking for $2 \mathrm{~h}$ at $37^{\circ} \mathrm{C}$ to allow expression of the resistance gene. Antibioticresistant transformants were selected on $7 \mathrm{H} 11$ agar (Difco) containing $5 \%$ ODAC, $0.5 \%$ glycerol and $10 \mu \mathrm{g}$ kanamycin sulphate $\mathrm{ml}^{-1}$ (Sigma) or $100 \mu \mathrm{g}$ hygromycin $\mathrm{ml}^{-1}$ (a gift from E. T. Seno, Eli Lilly, Indianapolis). For cloning in Escherichia coli, the strain DH5 (Woodcock et al., 1989) was used as host. Transformants were selected on $\mathrm{L}$ agar containing $50 \mu \mathrm{g}$ carbenicillin $\mathrm{ml}^{-1}$.

Extraction of genomic DNA. Genomic DNA was extracted from $M$. smegmatis $\mathrm{mc}^{2} 155$ by the salting-out method (Pospiech \& Neumann, 1995).

PFGE. Agarose plugs containing M. smegmatis cells were prepared, digested with AseI, and fractionated by PFGE as described for $S$. coelicolor (Kieser et al., 1992). The $0.5 \times$ Tris/borate/EDTA (TBE) electrophoresis buffer needed to be supplemented with $50 \mu \mathrm{M}$ thiourea (Sigma) to obtain sharp, high-molecular-mass bands (K. Dharmalingam, personal communication). The gels were subjected to electrophoresis for $24 \mathrm{~h}$ at $6 \mathrm{~V} \mathrm{~cm}^{-1}$ and $14{ }^{\circ} \mathrm{C}$. The pulse times were $5-25 \mathrm{~s}$ (linear ramp) at an angle of $120^{\circ}$.

Southern hybridization. Digested chromosomal DNA was fractionated on $0.8 \%$ agarose gels in TBE buffer and transferred onto Hybond-N membrane (Amersham) and hy- bridized as described in Sambrook et al. (1989). The final wash was in $0 \cdot 1 \times$ SSC at $67^{\circ} \mathrm{C}$.

PCR amplification. IS117 integration $\left(a t t_{\mathrm{B}}\right)$ sites were PCRamplified from non-transformed $M$. smegmatis genomic DNA in a Stratagene Robocycler using the following primers: A 1 (5'-CCGGATCCTACTTCGACCGTGGGCAG-3') and A2 (5'-GGAATTCGGTAGGGAGTCAGGCCGG-3') for site A; B1 (5'-GGAATTCGATCTCGGCGTACGGCAG-3') and B2 (5'-GGATATCCGTGCCTATCCCGACCTG-3') for site B; C1 (5'-GGATATCGATGATGCTCCGGAATCG-3') and C2 (5'-GAAGCTTGTGGTCGACCGGAAGGTG-3') for site C. Boehringer Mannheim Taq DNA polymerase and buffer were used in the reaction with the following conditions: denaturation at $96^{\circ} \mathrm{C}$ for $1 \mathrm{~min}$, annealing at $55^{\circ} \mathrm{C}$ (for site $\mathrm{C}$ ) or $60^{\circ} \mathrm{C}$ (for sites $\mathrm{A}$ and $\mathrm{B}$ ) for $2 \mathrm{~min}$, and extension at $72{ }^{\circ} \mathrm{C}$ for $1 \mathrm{~min}$; total cycles $=30$. The reaction was preceded by a hot start $\left(96{ }^{\circ} \mathrm{C}\right.$ for $5 \mathrm{~min}$ ) and was finished with a final extension reaction for $10 \mathrm{~min}$.

DNA sequencing. Plasmid DNA for double-strand sequencing was purified using the QIAGEN plasmid purification kit. PCR products for sequencing were extracted from agarose gels using the QIAquick gel extraction kit. Sequencing reactions were done using the Amersham Thermo Sequenase dye terminator sequencing $\mathrm{kit}$ and the oligonucleotide primers MC1 (5'-CAGCGGCGCCGGTCTCAGAGAGAG-3') and MC2 (5'-TCATGAGCACACCCTGGCAGCAGC-3').

\section{RESULTS AND DISCUSSION}

\section{Introduction of IS117 derivatives into M. smegmatis by electroporation}

Two IS117 derivatives, pIJ4696 and pIJ4697, were used (details in Fig. 1). They differ only in the orientation of the hyg gene, and they were useful to detect a possible dependence of the hygromycin resistance on external promoters. No hygromycin resistance was detected in $E$. coli because the Streptomyces promoter is not expressed. The two constructs were introduced into M. smegmatis $\mathrm{mc}^{2} 155$ by electroporation. Similar numbers of hygromycin-resistant colonies were obtained with pIJ4696 and pIJ4697, and no hygromycin-resistant colonies appeared in the transformation control without DNA. The autonomously replicating pAL5000 derivative pYUB12 (Snapper et al., 1988) was used as an internal control for the transformation frequency. In four independent experiments using $1 \mu \mathrm{g} \mathrm{pIJ} 4696$ and $0.5 \mu \mathrm{g}$ pYUB12, the transformation frequency of pIJ4696 was between 4 and $15 \%$ of that of pYUB12 $\left[0.5 \times 10^{5}\right.$ transformants $(\mu \mathrm{g} D N)^{-1}$. In $S$. lividans the transformation frequency of a minicircle derivative was only $0.2 \%$ of that of an autonomously replicating plasmid (Henderson et al., 1989).

\section{IS117 integrated into three specific sites in M. smegmatis}

Total DNA from 10 pIJ4696 and 10 pIJ4697 transformants was digested with EcoRI, fractionated on an agarose gel and probed with random prime labelled pIJ4696 or pIJ4697 DNA. Each plasmid has two EcoRI sites, one of which is in the hyg fragment (Fig. 1). Digestion of the circular plasmids gave two EcoRI 


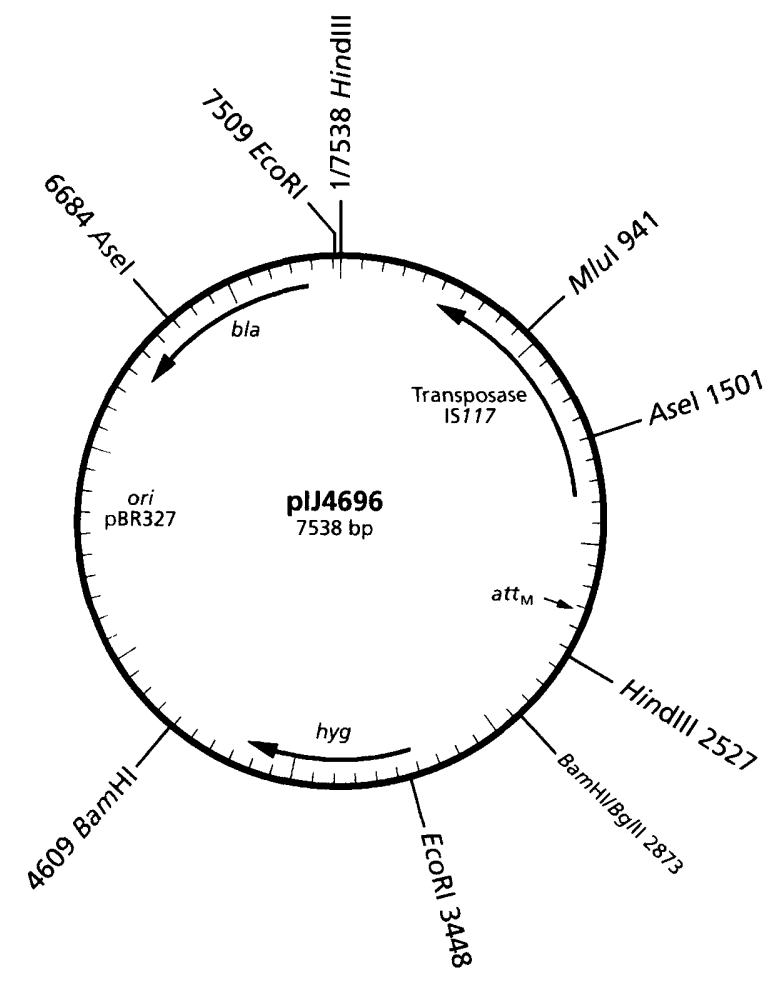

Fig. 1. Structure of plJ4696 (and plJ4697). plJ4696 is a hybrid between 15117 and pBR327; both linearized at their unique HindIII sites. The BamHI-Bg/ll hyg fragment was then cloned into the unique $B a m H I$ site in the tetracycline-resistance gene of pBR327 (at nucleotide 2873 there is neither a BamHI nor a Bg/ll site). plJ4697 differs from plJ4696 only in the orientation of the fragment containing the hyg gene. att ${ }_{\mathrm{M}}$, attachment site of 15117; bla, $\beta$-lactamase gene (carbenicillin resistance); hyg, hygromycin-resistance gene (phosphotransferase) of Streptomyces hygroscopicus; ori, origin of replication for $E$. coli, not functional in $M$. smegmatis. Scale, $100 \mathrm{bp}$ and $1 \mathrm{~kb}$ intervals.

fragments, one of which contained $a t t_{\mathrm{M}}$. In all 20 transformants the 'internal' fragment without $a t t_{\mathrm{M}}$ remained unchanged (Fig. 2). In 14 samples (labelled ' $\mathrm{s}$ ' in Fig. 2) the $a t t_{\mathrm{M}}$-containing fragment was replaced by two 'flanking' fragments of varying sizes that were always larger than the $a t t_{\mathrm{M}}-E c o \mathrm{RI}$ distances. This is the expected pattern for the transposition of a single complete plasmid into the genome. The remaining six samples (labelled ' $t$ ' in Fig. 2) contained an additional band corresponding in size to the uninterrupted $a t t_{\mathrm{M}}$ fragment at half the intensity of the internal fragment. This is the pattern expected for tandem insertion of two elements that was predominant in $S$. lividans (Henderson et al., 1989).

Allowing for differences between equivalent bands for pIJ4696 and pIJ4697 caused by the location of one of the EcoRI sites in the byg fragment, three patterns of flanking bands were observed among the independent transformants, indicating that IS117 had transposed into three specific sites, A, B and C. In each of the 20 transformants only one of the sites was occupied; 11 insertions were in site A (four tandem insertions), eight in site $B$ (two tandem insertions) and one in site $C$ (single insertion). There may be other additional infrequently occupied sites like site $C$ which we have not detected, but the preference seems to be for sites $\mathrm{A}$ and $\mathrm{B}$.

\section{PFGE to locate the att $\mathrm{B}_{\mathrm{B}}$ sites on $\boldsymbol{M}$. smegmatis genomic Asel fragments}

AseI, which cleaves the high $\mathrm{G}+\mathrm{C}$ Mycobacterium DNA infrequently, is suitable for analysis by PFGE. pIJ4696 and pIJ4697 contain two AseI sites, making it easy to localize the insertion points. Results from the ethidium-bromide-stained gels were confirmed by probing with the labelled plasmids (data not shown). Site $\mathrm{A}$ is in an approximately $225 \mathrm{~kb}$ Asel fragment of $M$. smegmatis, producing new flanking fragments of approximately $75 \mathrm{~kb}$ and $150 \mathrm{~kb}$. Sites $B$ and $C$ are in two different approximately $340-350 \mathrm{~kb}$ AseI fragments. New flanking bands of approximately 90 and $250 \mathrm{~kb}$ and approximately 90 and $260 \mathrm{~kb}$ were generated for insertions in sites $B$ and $C$, respectively.

\section{Levels of hygromycin resistance}

The strains were tested for their levels of antibiotic resistance by spot-inoculating 10 -fold dilutions of cultures onto $7 \mathrm{H} 11$ plates containing $0,5,10,20,40,80$, $100,200,300$ or $400 \mu \mathrm{g}$ hygromycin $\mathrm{ml}^{-1}$. Single colonies of untransformed $\mathrm{mc}^{2} 155$ failed to grow on $5 \mu \mathrm{g}$ hygromycin $\mathrm{ml}^{-1}$ and a dense patch inoculated with approximately $10^{5}$ cells failed to grow on $40 \mu \mathrm{g}$ hygromycin $\mathrm{ml}^{-1}$. Single colonies of all the transformed strains grew normally on $400 \mu \mathrm{g}$ hygromycin $\mathrm{ml}^{-1}$, irrespective of the site of integration, the orientation of the byg gene or the copy number. Therefore, it is unlikely that the observed target-site specificity was influenced by the selection of transformants on $100 \mu \mathrm{g}$ hygromycin $\mathrm{ml}^{-1}$.

\section{plJ4696 is stably maintained in M. smegmatis}

Starting with a single hygromycin-resistant colony, one pIJ4696 transformant of each type (single integrations in each site and tandem integration in site A) was propagated nonselectively for 60 doublings in $7 \mathrm{H} 9$ broth. Each culture was then plated for single colonies on $7 \mathrm{H} 11$ agar. All 200 tested colonies (50 from each transformant) were hygromycin resistant. By comparison, the autonomously replicating pAL5000 derivative was lost from $>70 \%$ of the culture under the same conditions (England et al., 1991).

\section{Circular forms of IS117 were not detected in $M$. smegmatis containing single insertions}

Circular transposition intermediates occur at a low but readily detectable frequency of one CCC molecule per 10-50 chromosomes in Streptomyces (Henderson et al., 1989; Lydiate et al., 1986). In M. smegmatis trans- 


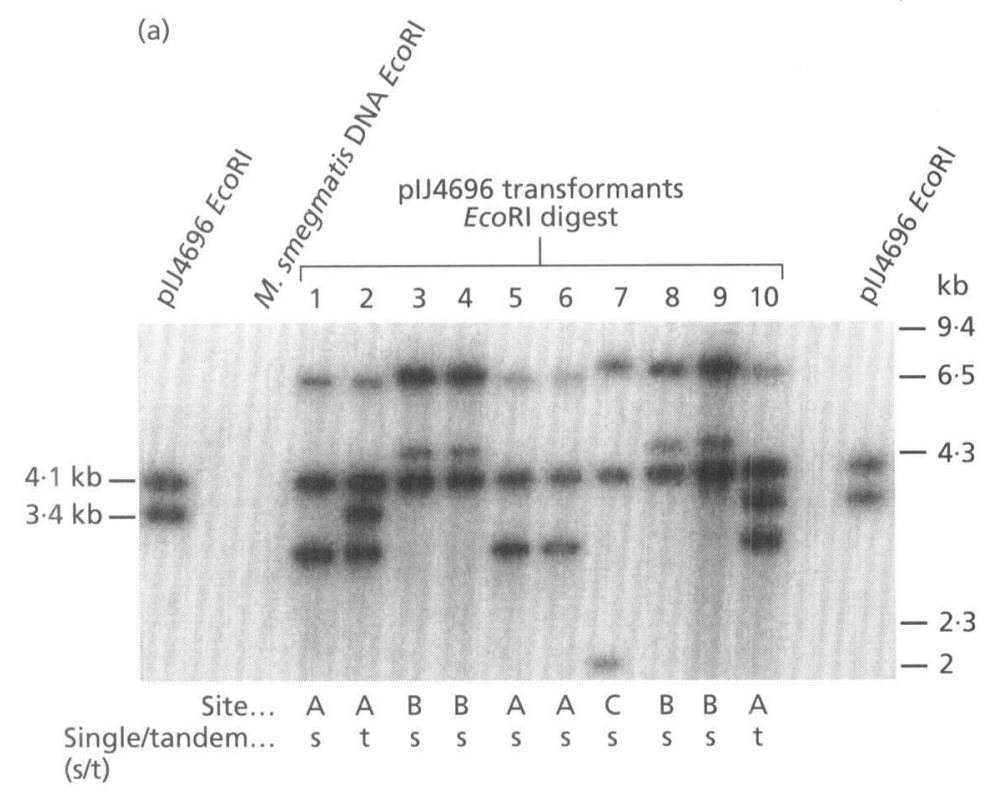

(b)

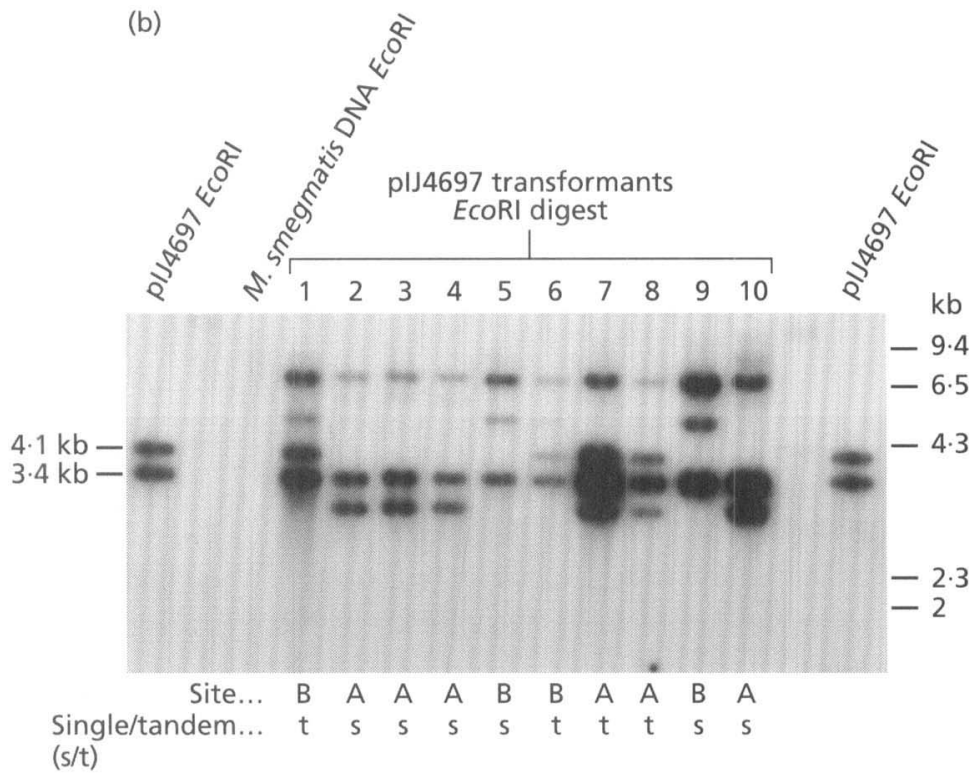

Fig. 2. Autoradiographs from Southern analysis of genomic DNA of hygromycinresistant transformants. (a) Independent plJ4696 transformants probed with labelled plJ4696; (b) independent plJ4697 transformants probed with labelled plJ4697. formants, they could not be detected in Southern blots of digested (Fig. 2) or undigested (data not shown) total DNA. Oligonucleotide primers MC1 and MC2, reading from both sides towards att ${ }_{\mathrm{M}}$, were used for PCR amplification. This produces a $265 \mathrm{bp}$ fragment both from circular forms and also from tandem copies. DNA from a transformant with tandem integrations which was used as a positive control gave a band of expected size. Low yields of products of different sizes were obtained from the transformants with single insertions at sites A, B and C. One of these faint bands co-migrated with the 265 bp positive control but after purification from the gel and reamplification, it gave a different HaeIII restriction pattern from the control. Therefore, circular IS117 derivatives could not be detected in $M$. smegmatis containing single insertions. This suggests that once IS117 is integrated excision is much less frequent than in Streptomyces. This may also explain why the elements did not transpose from the original insertion sites to the other sites to give multiple insertions.

\section{Cloning of the $\boldsymbol{M}$. smegmatis IS117 integration sites}

pIJ4696 has the pBR327 replication origin and the bla gene for selection in E. coli, and no Asp718 site. It was therefore possible to excise the plasmid together with flanking sequences by digestion of total DNA with Asp718. The digested samples were re-ligated at low DNA concentration $\left(200 \mathrm{ng} \mathrm{ml}^{-1}\right)$ and used to transform E. coli $\mathrm{DH} 5 \alpha$. Plasmids isolated from these transformants contained, as expected, a single Asp 718 site. The sizes of the plasmids containing tandem copies confirmed that two copies were present. No trans- 
(a)

\begin{tabular}{ll|l|l} 
S62247 & ATGCGGATGCGACACCGGG & AAG & AGGTCGGAGAGGGGACGC \\
S62248 & CGCCTTCGTGACCTCGGTC & AAG & GAGTGCGCCGCCACGCGC \\
S62250 & CGCGATGCCGCTGCCCGTC & AAG & GAGTGCGCCGCCACGCGC \\
S62242 & GAGTGTGTGCGGGCCGGTC & AAG & GGTGAAACGCCGTGCACC \\
S62243 & CGCGATGCCGCTGCCCGTC & AAG & GTGGAGACGAACAGGCCC \\
S62245 & CCTGAGGACGGCCCTGGTC & AAG & GGAAGTGGGCCGGCTAC \\
S62249 & CCTCGCGTCGTACGGCGTC & AAG & GGACTCGGCTGGCTCGCA \\
Site A & GGCACGTGCCGTCAGTGTC & AAG & GTGGAAACGAGCAGATCT \\
Consensus & cgc--tgtcggtccccGtC & AAG & ggg--cgeg-ccag-cCC
\end{tabular}

(b)

Slp site

S62244

S62241

S62246

Site B

Site C

Consensus

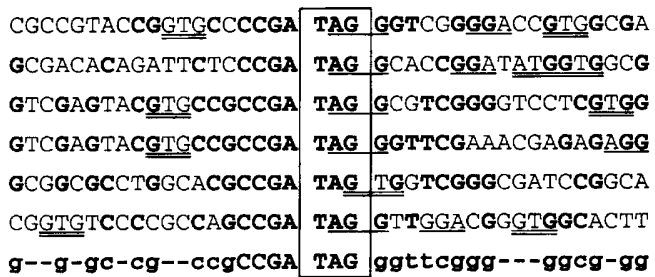

Fig. 3. Comparison of the S. lividans and M. smegmatis 15117 integration sites. Alignment of sequences of: (a) $M$. smegmatis site $A$ and $S$. lividans secondary integration sites; (b) $M$. smegmatis sites B and $C$ and $S$. lividans preferred (SIp) and secondary integration sites. The sequences with $\mathrm{EMBL}$ accession numbers $562241-50$ are $S$. lividans secondary integration sites. The sequences in boxes are the crossover points; putative RBSs (sequences with at least $3 \mathrm{bp}$ homology to the 3 ' end of $16 \mathrm{~S}$ rRNA) are underlined; and all ATG and GTG start codons are double-underlined. Bases identical in $50 \%$ or more of the sequences are indicated in bold.

formants were obtained from the single insertion in site C. It was, however, possible to clone the right and left border sequences separately using Bam HI and $M l u \mathrm{I}$, respectively. It is noteworthy that none of the transformants, not even those from strains containing tandem insertions, contained the original plasmid that might have excised naturally from the M. smegmatis chromosome.

\section{Sequences of the IS117 integration sites}

The above plasmids and two 24-mer primers, MC1 and $M C 2$, reading from each side towards att ${ }_{\mathrm{M}}$ were used for sequencing. The sequences confirmed that, as in $S$. lividans, integration was via the known att ${ }_{\mathrm{M}}$ site, that there was no target site duplication, and that the orientation of IS117 at each site was fixed. Fig. 3 shows an alignment at the crossover point of the three $M$. smegmatis target sites with those already known from $S$. lividans (Smokvina \& Hopwood, 1993). The sequence $\mathrm{AGg}$ to the right of the crossover point is conserved in all 14 sequences. The sequence similarity extends to the left if the sequences are subdivided into two groups. Group $A$, which includes site $A$, has the consensus GtcAAGg and Group B, which includes sites B and C, has the consensus gCCGATAGg. These sequences probably occur randomly several times in the $M$. smegmatis genome. Either most of such sites are in essential regions or these short consensus sequences do not alone specify target sites. Compare-Dotblot sequence analysis (UWGCG package; Devereux et al., 1984) to detect direct and inverted repeats did not reveal any features that were similar in all or most of these sequences.

The IS117 target sequences $\left(a t t_{\mathrm{B}}\right)$ were compared with the sequence databases. The sequence downstream of the crossover point at site $\mathrm{C}$ matches the translation initiation region and amino-terminus of the $M y c o-$ bacterium tuberculosis aminopeptidase gene (pepD), which also has a homologue in $S$. lividans. A putative ribosome-binding site (RBS) is present immediately downstream of the crossover point (underlined in Fig. 3). The S. lividans att $t_{\mathrm{B}}$ sites also have putative RBS and GTG start codons. No perfect database matches were found for sites A and B, but both have a possible GTG start codon to the right of the crossover point. The $\mathrm{G}+\mathrm{C}$ content of the three target sites (100 nucleotides) is $71-72 \%$, only slightly higher than the $67 \%$ average for M. smegmatis. High G + C DNA contains few outof-frame stop codons but protein coding regions can be recognized reliably because most amino acid codons containing $G$ or $C$ in positions one and three are used preferentially (Bibb et al., 1984). All the sites seem to be in untranslated regions. It is therefore likely that IS117 targets, at least partly, translation initiation signals, as was described by Doran et al. (1997) for IS900, which has a similar transposase.

\section{IS117 integration into $M$. smegmatis did not cause deletions}

Insertion of IS117 into secondary att $t_{\mathrm{B}}$ sites in S. lividans frequently caused deletions at the target site (Smokvina \& Hopwood, 1993). The deletions may have arisen from two IS117 derivatives transposing into the chromosome a few kilobases apart but in the same orientation. Efficient recombination between the two elements would delete the intervening (non-essential) DNA and produce the observed strains containing IS117 flanked by noncontiguous DNA. To test for deletions in M. smegmatis transformants, the distance between the sequences that flank inserted IS117 was estimated in the non-transformed strain using PCR amplification with primers homologous to the left and right flanking sequences. The primers used are described in Methods. The sizes of the observed amplification products were as predicted from the sequence, and sequencing of the PCR products proved that they did contain the $a_{t} t_{\mathrm{B}}$ sites $\mathrm{A}, \mathrm{B}$ or $\mathrm{C}$. Therefore, IS117 did not cause deletions in M. smegmatis.

\section{Concluding remarks}

IS117 always integrated in the same orientation into one of three sites in $M$. smegmatis, and the hygromycin resistance was independent of the orientation of the gene or the site of insertion. This, and the high stability in the absence of antibiotic selection, make pIJ4696 and 
pIJ4697, which contain unique BamHI cloning sites, promising vectors for cloning foreign genes in $M$. smegmatis, and possibly other mycobacteria. Other potentially useful IS117 vector derivatives have also been described (Motamedi et al., 1995). IS900 from M. paratuberculosis, which integrates into several genomic sites in $M$. smegmatis, has also been used as a stable integrative vector (Dellagostin et al., 1993; England et al., 1991). The relative transformation frequencies obtained with pIJ4696 were $4-15 \%$ of that of the autonomously replicating pYUB12, which compare favourably with the values of $0.02-0.05 \%$ reported for the IS900 derivatives.

Surprisingly, there are two different IS117 att B $_{\mathrm{B}}$ consensus sequences of only $7-9 \mathrm{bp}$ in length. Since these sites would be expected to occur several times in the $M$. smegmatis genome, it is likely that there are additional sequence features that are recognized by the IS117 transposase. No perfect direct or inverted repeats are present in all the att $_{\mathrm{B}}$ sequences. It seems, however, that IS117 has a partial preference for translational start sites as was observed previously for IS900 (Doran et al., 1997). IS900 has the sequence AAGGA at its $3^{\prime}$ end which could function as a RBS while in IS117 the sequence GGA is present 1 bp upstream of the crossover point.

\section{ACKNOWLEDGEMENTS}

We thank Mervyn Bibb, Mark Buttner, Keith Chater, David Hopwood and Mike Merrick for their helpful comments on this manuscript. A.B. is supported by a PhD studentship from the John Innes Foundation, Norwich, UK.

\section{REFERENCES}

Ashby, M. K. \& Bergquist, P. L. (1990). Cloning and sequence of IS1000, a putative insertion sequence from Thermus thermophilus HB8. Plasmid 24, 1-11.

Bartlett, D. H. \& Silverman, M. (1989). Nucleotide sequence of IS492, a novel insertion sequence causing variation in extracellular polysaccharide production in the marine bacterium Pseudomonas atlantica. J Bacteriol 171, 1763-1766.

Bibb, M. J., Findlay, P. R. \& Johnson, M. W. (1984). The relationship between base composition and codon usage in bacterial genes and its use for the simple and reliable identification of protein-coding sequences. Gene 30, 157-166.

Bruton, C. J. \& Chater, K. F. (1987). Nucleotide sequence of IS110, an insertion sequence of Streptomyces coelicolor A3(2). Nucleic Acids Res 15, 7053-7065.

Dellagostin, O. A., Wall, S., Norman, E., O'Shaughnessy, T., Dale, J. W. \& McFadden, J. (1993). Construction and use of integrative vectors to express foreign genes in mycobacteria. Mol Microbiol 10, 983-993.

Devereux, J., Haeberli, P. \& Smithies, O. (1984). A comprehensive set of sequence analysis programs for the VAX. Nucleic Acids Res 12, 387-395.

Doran, T., Tizard, M., Millar, D., Ford, J., Sumar, N., Loughlin, M. \& Hermon-Taylor, J. (1997). IS900 targets translation initiation signals in Mycobacterium avium subsp. paratuberculosis to facilitate expression of its hed gene. Microbiology 143, 547-552.

England, P. M., Wall, S. \& McFadden, J. (1991). IS900-promoted stable integration of a foreign gene into mycobacteria. Mol Microbiol 5, 2047-2052.

Freiberg, C., Fellay, R., Bairoch, A., Broughton, W. J., Rosenthal, A. \& Perret, X. (1997). Molecular basis of symbiosis between Rhizobium and legumes. Nature 387, 394-401.

Fulks, K. A., Marrs, C. F., Stevens, S. P. \& Green, M. R. (1990). Sequence analysis of the inversion region containing the pilin genes of Moraxella bovis. J Bacteriol 172, 310-316.

Green, E. P., Tizard, M. L. V., Moss, M. T., Thompson, J., Winterbourne, D. J., McFadden, J. J. \& Hermon-Taylor, J. (1989). Sequence and characteristics of IS900, an insertion element identified in a human Crohn's disease isolate of Mycobacterium paratuberculosis. Nucleic Acids Res 17, 9063-9073.

Henderson, D. J., Lydiate, D. J. \& Hopwood, D. A. (1989). Structural and functional analysis of the mini-circle, a transposable element of Streptomyces coelicolor A3(2). Mol Microbiol 3, 1307-1318.

Henderson, D. J., Brolle, D.-F., Kieser, T., Melton, R. E. \& Hopwood, D. A. (1990). Transposition of IS117 (the Streptomyces coelicolor A3(2) mini-circle) to and from a cloned target site and into secondary chromosomal sites. Mol Gen Genet 224, 65-71.

Hoover, T. A., Vodkin, M. H. \& Williams, J. C. (1992). A Coxiella burnetti repeated DNA element resembling a bacterial insertion sequence. J Bacteriol 174, 5540-5548.

Kieser, H. M., Kieser, T. \& Hopwood, D. A. (1992). A combined genetic and physical map of the Streptomyces coelicolor A3(2) chromosome. J Bacteriol 174, 5496-5507.

Kulakova, A. N., Larkin, M. J. \& Kulakov, L. A. (1997). The plasmid-located haloalkane dehalogenase gene from $R$ hodococcus rhodochrous NCIMB 13064. Microbiology 143, 109-115.

Kunze, Z. M., Wall, S., Appelberg, R., Silva, M. T., Portaels, F. \& McFadden, J. J. (1991). IS901, a new member of a widespread class of atypical insertion sequences, is associated with pathogenicity in Mycobacterium avium. Mol Microbiol 5, 2265-2272.

Leskiw, B. K., Mevarech, M., Barritt, L. S., Jensen, S. E., Henderson, D. J., Hopwood, D. A., Bruton, C. J. \& Chater, K. F. (1990). Discovery of an insertion sequence, IS116, from Streptomyces clavuligerus and its relatedness to other transposable elements from actinomycetes. J Gen Microbiol 136, 1251-1258.

Lydiate, D. J., Ikeda, H. \& Hopwood, D. A. (1986). A 2.6 kb DNA sequence of Streptomyces coelicolor A3(2) which functions as a transposable element. Mol Gen Genet 203, 79-88.

Moss, M. T., Malik, Z. P., Tizard, M. L. V., Green, E. P., Sanderson, J. D. \& Hermon-Taylor, J. (1992). IS902, an insertion element of the chronic-enteritis-causing Mycobacterium avium subsp. silvaticum. J Gen Microbiol 138, 139-145.

Motamedi, H., Shafiee, A. \& Cai, S.-J. (1995). Integrative vectors for heterologous gene expression in Streptomyces spp. Gene 160, 25-31.

Pospiech, A. \& Neumann, B. (1995). A versatile quick-prep of genomic DNA from gram-positive bacteria. Trends Genet 11 , 217-218.

Rakin, A. \& Heesemann, J. (1995). Virulence-associated fyuA/irp2 gene cluster of Yersinia enterocolitica biotype $1 \mathrm{~B}$ carries a novel insertion sequence IS1328. FEMS Microbiol Lett 129, 287-292.

Sambrook, J., Fritsch, E. F. \& Maniatis, T. (1989). Molecular Cloning: a Laboratory Manual, 2nd edn. Cold Spring Harbor, NY: Cold Spring Harbor Laboratory.

Smokvina, T. \& Hopwood, D. A. (1993). Analysis of secondary integration sites for IS117 in Streptomyces lividans and their role in the generation of chromosomal deletions. Mol Gen Genet 239, 90-96. 
Smokvina, T., Henderson, D. J., Melton, R. E., Brolle, D.-F., Kieser, T. \& Hopwood, D. A. (1994). Transposition of IS 117 , the $2 \cdot 5 \mathrm{~kb}$ Streptomyces coelicolor A3(2) 'minicircle': roles of open reading frames and origin of tandem insertions. Mol Microbiol 12, 459-468.

Snapper, S. B., Lugosi, L., Jekkel, A., Melton, R. E., Kieser, T., Bloom, B. R. \& Jacobs, W. R., Jr (1988). Lysogeny and transformation in mycobacteria: stable expression of foreign genes. Proc Natl Acad Sci USA 85, 6987-6991.

Snapper, S. B., Melton, R. E., Kieser, T., Mustafa, S. \& Jacobs, W. R., Jr (1990). Isolation and characterization of efficient plasmid transformation mutants of Mycobacterium smegmatis. Mol Microbiol 4, 1911-1919.
Woodcock, D. M., Crowther, P. J., Doherty, J., Jefferson, S., DeCruz, E., Noyer-Weidner, M., Smith, S. S., Michael, M. Z. \& Graham, M. W. (1989). Quantitative evaluation of Escherichia coli host strains for tolerance to cytosine methylation in plasmid and phage recombinants. Nucleic Acids Res 17, 3469-3478.

Zhu, J. \& Winans, S. C. (1998). Activity of the quorum-sensing regulator TraR of Agrobacterium tumefaciens is inhibited by a truncated, dominant defective TraR-like protein. Mol Microbiol 27, 289-297.

Received 26 October 1998; revised 27 January 1999; accepted 2 February 1999. 